\title{
HETEROSE EM CAJUEIRO ANÃO PRECOCE
}

\author{
JOSÉ JAIME VASCONCELOS CAVALCANTI ${ }^{1}$ \\ JOÃO RIBEIRO CRISÓSTOMO ${ }^{2}$ \\ LEVI DE MOURA BARROS ${ }^{2}$ \\ JOÃO RODRIGUES DE PAIVA ${ }^{2}$
}

\begin{abstract}
RESUMO - Esse trabalho foi conduzido com o objetivo de avaliar a heterose no cajueiro (Anacardium occidentale L.) anão precoce. $\mathrm{O}$ experimento foi composto por seis clones parentais (CCP 06, CCP 09, CCP 76, CCP 1001, C1P3 e P399E) e 18 combinações híbridas. Utilizou-se delineamento de blocos casualizados, com duas repetições e cinco plantas por parcela. A heterose média foi de $12,09 \%, 19,38 \%, 98,01 \%, 96,97 \%$ e $2,11 \%$, respectivamente, para altura da planta, diâmetro da copa, número de castanha por planta, produtivi-
\end{abstract}

dade de castanha e peso médio de castanha, indicando presença de vigor híbrido nos cruzamentos, para todos os caracteres, exceto para peso médio de castanha, demonstrando a importância de sua exploração, com perspectivas de avanços genéticos sobre caracteres da cultura do caju. A consequiência seria a obtenção de clones comerciais com características de produção desejáveis e a formação de populações-base para o programa de melhoramento populacional. Os híbridos CCP 06 x C1P3, CCP 09 x P399E e CCP 09 x CCP 06 são os mais promissores.

TERMOS PARA INDEXAÇÃO: Anacardium occidentale L., híbridação, fruticultura, melhoramento.

\section{HETEROSIS IN PRECOCIOUS DWARF CASHEW}

\begin{abstract}
The objective of this work was to evaluate the heterosis in dwarf cashew (Anacardium occidentale L.). The experiment had six parent clones (CCP 06, CCP 09, CCP 76, CCP 1001, C1P3, and $\mathrm{P} 399 \mathrm{E})$ and 18 hybrid plants. A randomized complete block experimental design with two replications and five plants per plot was used. The average heterosis was $12 \%, 19 \%, 98 \%, 97 \%$, and $-2 \%$, for the parent clones, based on the traits plant height, canopy diameter, number
\end{abstract}

of nuts per plant, nut yield, and nut weight. It should be pointed out the presence of hybrid vigor in all crosses for all traits, except nut weight. This stresses the importance of hybrid vigor exploration, with perspectives of significant genetic improvement of the cashew culture, by obtaining superior commercial clones and establishing basepopulations for the population breeding program. The hybrid combinations CCP 06 x C1P3, CCP 09 x P399E, and CCP 09 x CCP 06 are the most promising.

INDEX TERMS: Anacardium occidentale L., hybridization, plant breeding.

\section{INTRODUÇÃO}

Desde o final do século XIX, tem-se observado que cruzamento entre indivíduos, notadamente não aparentados, resulta em descendentes mais vigorosos. Tal fenômeno tem sido chamado de heterose ou vigor híbrido e é definido como a superioridade dos filhos em relação à média dos pais (Paterniani, 1974). A exploração da heterose tem despertado grande atenção dos pesquisadores e foi a principal mudança ocorrida na agricultura no século XX, tendo o maior impacto produzido na produção do milho híbrido, que a partir de
1920, começou a ser extensamente utilizado nos Estados Unidos.

O termo heterose foi originalmente proposto por Shull (1908), citado por Brewbaker (1969), para descrever o vigor de híbrido manifestado em organismos heterozigotos, derivados do cruzamento entre indivíduos genotipicamente divergentes, ou seja, a expressão genética dos efeitos da hibridação. Em geral, o efeito principal esperado está relacionado a um aumento substancial de produtividade. Porém, um grande número de outros caracteres agronômicos economicamente importantes são, também, melhorados pela hibridação (Allard, 1971).

1. Engenheiro Agrônomo, M.Sc., Embrapa-Centro Nacional de Pesquisa de Agroindústria Tropical (CNPAT), Caixa Postal 3761, 60511-110 - Fortaleza, CE. jaime@cnpat.embrapa.br

2. Engenheiro Agrônomo, Dr., CNPAT. 
A exploração da heterose apresenta as seguintes vantagens: a) permite a associação, no mesmo indivíduo, de caracteres que estão separados em diferentes genitores; b) permite a obtenção, em prazo relativamente curto, de genótipos com características desejáveis que podem ser disponibilizados aos produtores; c) permite a obtenção de um melhoramento genético substancial, possivelmente, em parte, pela utilização de interações gênicas que só podem ser aproveitadas na geração híbrida; d) permite obter produtos uniformes e bempadronizados; e) a geração $F_{1}$ geralmente apresenta maior homeostase, ou seja, menor interação por ambiente do que ocorre com genótipos mais homozigóticos, refletindo numa adaptabilidade mais ampla do híbrido, cujas produções oscilam menos entre locais e anos distintos (Paterniani, 1974). Strickberger (1974) supõe que essa maior adaptabilidade dos híbridos é refletida, independente de quaisquer que sejam as causas fisiológicas, devido ao heterozigoto estar mais bem protegido (tamponado), de modo que as variações ambientais durante o desenvolvimento não afetam tanto o indivíduo quanto o homozigoto.

Os clones de cajueiro do tipo anão precoce têm proporcionado grande impulso à cultura do caju no Brasil, por apresentarem maior produtividade, maior precocidade e menor porte em relação ao tipo comum. Todavia, outros caracteres de importância econômica, como: resistência a doenças, qualidade e peso da castanha e da amêndoa e qualidade do pedúnculo, necessitam de maiores investigações na área da genética. O cruzamento entre clones de cajueiro resulta em progênies segregantes, pelo fato de ser cada indivíduo, em essência, um híbrido. Em decorrência, os indivíduos obtidos formam um conjunto semelhante a uma geração $F_{2}$, em que a segregação é mais intensa e deve ser iniciada a seleção para fixação imediata dessas combinações genéticas (Barros et al., 1999).

No cajueiro, a heterose ou vigor híbrido apresenta vantagem adicional de poder ser capitalizada e explorada de imediato, em qualquer etapa do programa, por meio da multiplicação assexuada, após a obtenção do híbrido. Com este trabalho, objetivou-se avaliar o potencial heterótico de seis genótipos de cajueiro anão precoce e suas respectivas combinações híbridas.

\section{MATERIAL E MÉTODOS}

O estudo foi realizado no Campo Experimental de Pacajus, da Embrapa Agroindústria Tropical, localizado no município de Pacajus, $\mathrm{CE}$, em um experimento composto de seis genitores, representados por progênies de polinização livre (PCP 06 - Progênie de Cajueiro de Pacajus, PCP 76, PCP 09, PCP 1001, PC1P3, PP399E) dos clones CCP 06 - Clone de Cajueiro de Pacajus, CCP 09, CCP 76, CCP 1001, C1P3 e P399E e 18 híbridos, obtidos por meio de cruzamentos controlados entre esses genótipos, totalizando 24 tratamentos. Utilizaram-se o delineamento de blocos casualizados, duas repetições, cinco plantas por parcela, espaçadas em $7 \mathrm{~m} \mathrm{x}$ $7 \mathrm{~m}$. O plantio definitivo foi realizado em junho de 1991 e o experimento, conduzido em regime de sequeiro.

Os caracteres avaliados foram: altura da planta (AP), diâmetro da copa (DC), produtividade de castanhas (PROD), número de castanhas por planta (NC) e peso médio de castanha (PC), obtidos no $4^{\circ}$ e $6^{\circ}$ ano de idade para PROD, NC e PC e no $6^{\circ}$ ano para AP e DC. Efetuaram-se análises de variância por idade e conjunta, no esquema de parcela subdividida no tempo (Steel \& Torrie, 1980). O desempenho do híbrido foi determinado de acordo com a expressão proposta por Fehr (1987):

$$
\text { Heterose }(\%)=\frac{\mathrm{F} 1-\mathrm{MP}}{\mathrm{MP}} \times 100,
$$

Em que heterose $(\%)$ - percentagem de heterose em relação à média dos pais; $\mathrm{F}_{1}$ - desempenho do híbrido e MP - média dos pais.

\section{RESULTADOS E DISCUSSÃO}

A análise de variância demonstrou efeito de tratamento significativo para todos os caracteres (Tabela 1). Por outro lado, os efeitos de ano e da interação tratamentos $\mathrm{x}$ anos não apresentaram significância $(\mathrm{P}>$ $0,05)$, indicando que não há diferenças entre os anos de avaliação e que os tratamentos apresentaram comportamentos coincidentes ao longo dos anos.

O desdobramento do efeito de tratamento permitiu verificar que apenas os caracteres altura da planta e peso de castanha apresentaram diferenças significativas para o efeito de pais, indicando comportamento diferencial entre os genitores. Por outro lado, apenas os caracteres número de castanhas por planta, produtividade e diâmetro da copa foram significativos para os efeitos de híbridos e de pais vs. híbridos, indicando a importância da exploração do vigor híbrido em tais caracteres.

Nas Tabelas 2 e 3, encontram-se os valores de heterose para todos os caracteres em estudo. Os resultados obtidos variaram de $-13,50 \%$ a $43,60 \%$, para o ca-

Ciênc. agrotec., Lavras. V.27, n.3, p.565-570, maio/jun., 2003 
ráter altura de planta e de $-7,47 \%$ a $60,27 \%$ para o diâmetro da copa, sendo a combinação híbrida CCP 06 x C1P3 a mais expressiva (Tabela 2); de $-45,85 \%$ a $321,22 \%$ para o número de castanhas/planta; $-50,35 \%$ a $348,87 \%$, para a produtividade de castanhas e de $16,34 \%$ a $13,93 \%$, para o peso de castanha (Tabela 3). O híbrido que mais se sobressaiu para número de castanhas e produtividade foi originado do CCP 09 x CCP 06, ao passo que o CCP 06 x C1P3 expressou melhor resultado para peso médio da castanha.

A heterose média foi de $12,09 \%, 19,38 \%$, $98,01 \%, 96,97 \%$ e $-2,11 \%$, respectivamente, para altura de planta, diâmetro da copa, número de castanhas por planta, produtividade de castanhas e peso de castanha, indicando presença de vigor híbrido nos cruzamentos entre os pais de cajueiro anão precoce, para todos os caracteres, exceto para o peso de castanha. Valores expressivos de heterose também foram detectados na cultura do cajueiro por Damodaran (1975), Manoj \& George (1993) e Cavalcanti et al., (2000). Esse último autor observou valores da heterose média de $20,00 \%$, $31,93 \%, 120,77 \%, 192,25 \%, 14,69 \%$, respectivamente, para altura de planta, diâmetro da copa, número e pro- dução de castanhas, peso de castanha, em um experimento de híbridos de cajueiro anão x comum, indicando presença de considerável divergência genética entre os grupos de cajueiro anão precoce e comum.

A manifestação da heterose geralmente depende da divergência genética entre as variedades parentais. Se a heterose manifestada no cruzamento de duas variedades parentais é relativamente alta, conclui-se que esses parentais são geneticamente divergentes em relação a outro cruzamento de variedades que manifestam baixas ou nenhuma heterose em suas descendências (Hallauer \& Miranda Filho, 1981).

Os dados do presente trabalho podem ser comparados com os obtidos por Cavalcanti et al., (2000). Esse autor observou igualmente menor divergência genética entre os híbridos anão $\mathrm{x}$ anão que os anão x comum. Isso já era esperado, pois os clones de cajueiro anão precoce CCP 06, CCP 09, CCP 76 e CCP 1001 são materiais obtidos de progênies de meios-irmãos, ao passo que o C1P3 e o P399E são descendentes desses, sendo, portanto, genótipos altamente aparentados. Isso explica também os valores negativos detectados para a heterose em alguns casos.

TABELA 1 - Análise de variância para altura da planta (AP) e diâmetro da copa (DC), no sexto ano de idade das plantas, e conjunta (parcela subdividida no tempo) para número (NC), produtividade (PROD) e peso médio de castanhas (PC).

\begin{tabular}{lrccccc}
\hline & & \multicolumn{5}{c}{ Quadrados médios } \\
\cline { 3 - 7 } Fontes de variação & G.L. & AP(m) & DC $(\mathbf{m})$ & $\mathbf{N C}$ & PROD $\left(\mathbf{k g ~ h a}^{-\mathbf{1}}\right)$ & PC $(\mathbf{g})$ \\
\hline Bloco & 1 & 0,540 & 3,912 & 66714,6 & 110209,4 & 1,212 \\
Tratamento (T) & 23 & $0,188^{*}$ & $0,792^{* *}$ & $10558,2^{*}$ & $14937,0^{* *}$ & $3,138^{* *}$ \\
Pais (P) & 5 & $0,243^{*}$ & 0,450 & 2124,1 & 2952,4 & $9,824^{* *}$ \\
Híbridos (H) & 17 & 0,165 & $0,740^{*}$ & $11125,2^{*}$ & $15303,2^{*}$ & 1,287 \\
P vs. H & 1 & 0,297 & $3,379^{* *}$ & $43090,1 * *$ & $68634,4^{* *}$ & 1,180 \\
Erro a & 23 & 0,090 & 0,266 & 4592,8 & 6969,3 & 1,125 \\
Anos (A) & 2 & - & - & 10541,5 & 24481,7 & 8,596 \\
Erro b & 2 & - & - & 2059,4 & 5311,7 & 2,007 \\
T x A & 46 & - & - & 1181,5 & 1811,0 & 0,463 \\
Erro c & 46 & - & - & 860,4 & 1275,9 & 0,419 \\
\hline Média & & 1,99 & 4,04 & 79,74 & 103,48 & 6,73 \\
CV (\%) & & 15,14 & 12,78 & 36,79 & 34,52 & 9,62 \\
\hline
\end{tabular}

$*$ e ** Significativo a 5 e $1 \%$, respectivamente, pelo teste $\mathbf{F}$. 
TABELA 2 - Média dos híbridos anão x anão, dos pais e estimativa da heterose para altura da planta (AP) e diâmetro do caule (DC) no sexto ano de idade das plantas (1997).

\begin{tabular}{|c|c|c|c|c|c|c|}
\hline \multirow[b]{2}{*}{ Tratamentos } & \multicolumn{3}{|c|}{$\mathbf{A P}(\mathbf{m})$} & \multicolumn{3}{|c|}{$\mathrm{DC}(\mathrm{m})$} \\
\hline & Média & $\begin{array}{l}\text { Média dos } \\
\text { pais }\end{array}$ & $\begin{array}{c}\text { Heterose } \\
(\%)\end{array}$ & Média & $\begin{array}{l}\text { Média dos } \\
\text { pais }\end{array}$ & $\begin{array}{c}\text { Heterose } \\
(\%)\end{array}$ \\
\hline \multicolumn{7}{|l|}{ Híbridos } \\
\hline ССР 06 x ССР 76 & 1,79 & 1,71 & 5,18 & 4,79 & 3,35 & $42,73^{*}$ \\
\hline ССР 06 x ССР 09 & 1,72 & 1,46 & $17,81 *$ & 3,89 & 3,27 & $19,05^{*}$ \\
\hline CCP $06 \times$ C1P3 & 2,58 & 1,80 & $43,60 *$ & 5,29 & 3,30 & $60,27 *$ \\
\hline CCP 06 x P399E & 1,99 & 1,76 & $12,91 *$ & 4,97 & 3,87 & $28,59^{*}$ \\
\hline CCP 76 x CCP 1001 & 2,00 & 2,09 & $-4,46$ & 3,47 & 3,64 & $-4,62$ \\
\hline CCP 76 x C1P3 & 2,47 & 1,94 & $27,21 *$ & 4,82 & 3,32 & $45,18^{*}$ \\
\hline СCР 76 x P399E & 1,70 & 1,91 & $-10,88^{*}$ & 3,72 & 3,89 & $-4,35$ \\
\hline CCP 09 x CCP 1001 & 1,83 & 1,85 & $-0,99$ & 4,03 & 3,55 & $13,33^{*}$ \\
\hline CCP 09 x C1P3 & 1,83 & 1,70 & 7,71 & 3,74 & 3,24 & $15,57^{*}$ \\
\hline CCP 09 x P399E & 2,08 & 1,66 & $24,81 *$ & 4,51 & 3,80 & $18,42 *$ \\
\hline CCP 1001 x CCP 06 & 2,27 & 1,95 & $16,51^{*}$ & 4,59 & 3,61 & $27,00 *$ \\
\hline CCP 1001 x CCP 76 & 2,05 & 2,09 & $-2,07$ & 3,37 & 3,64 & $-7,47$ \\
\hline ССР 1001 x CCP 09 & 2,23 & 1,85 & $20,78^{*}$ & 4,07 & 3,55 & $14,49 *$ \\
\hline CCP 1001 x C1P3 & 1,89 & 2,19 & $-13,50 *$ & 3,58 & 3,58 & $-0,05$ \\
\hline CCP 1001 x P399E & 2,41 & 2,15 & $11,82^{*}$ & 3,84 & 4,15 & $-7,40$ \\
\hline ССР 76 x ССР 06 & 2,25 & 1,71 & $31,96^{*}$ & 4,81 & 3,35 & $43,33 *$ \\
\hline ССР 09 x ССР 06 & 1,96 & 1,46 & $33,90^{*}$ & 4,63 & 3,27 & $41,81 *$ \\
\hline ССР 09 x ССР 76 & 1,53 & 1,61 & $-4,67$ & 3,39 & 3,29 & 2,89 \\
\hline \multicolumn{7}{|l|}{ Pais } \\
\hline PCP 06 & 1,56 & - & - & 3,33 & - & - \\
\hline PCP 76 & 1,85 & - & - & 3,38 & - & - \\
\hline РCP 09 & 1,36 & - & - & 3,21 & - & - \\
\hline PCP 1001 & 2,34 & - & - & 3,90 & - & - \\
\hline PC1P3 & 2,03 & - & - & 3,27 & - & - \\
\hline PP399E & 1,97 & - & - & 4,40 & - & - \\
\hline Heterose média $(\%)$ & - & - & $12,09^{*}$ & - & - & $19,38^{*}$ \\
\hline
\end{tabular}

*Significativo a $5 \%$ pelo teste $t$.

Ciênc. agrotec., Lavras. V.27, n.3, p.565-570, maio/jun., 2003 
TABELA 3 - Média dos híbridos anão x anão, dos pais e estimativa da heterose para número (NC), produtividade (PROD) e peso médio de castanhas (PC).

\begin{tabular}{|c|c|c|c|c|c|c|c|c|c|}
\hline \multirow[b]{2}{*}{ Tratamentos } & \multicolumn{3}{|c|}{ NC } & \multicolumn{3}{|c|}{ PROD $\left(\mathrm{kg} \mathrm{ha}^{-1}\right)$} & \multicolumn{3}{|c|}{ PC (g) } \\
\hline & Média & $\begin{array}{l}\text { Média } \\
\text { dos pais }\end{array}$ & $\begin{array}{c}\text { Heterose } \\
(\%)\end{array}$ & Média & $\begin{array}{l}\text { Média } \\
\text { dos pais }\end{array}$ & $\begin{array}{c}\text { Heterose } \\
(\%)\end{array}$ & Média & $\begin{array}{l}\text { Média } \\
\text { dos pais }\end{array}$ & $\begin{array}{c}\text { Heterose } \\
(\%)\end{array}$ \\
\hline \multicolumn{10}{|l|}{ Híbridos } \\
\hline ССР 06 x ССР 76 & 123,10 & 40,68 & $202,58 *$ & 134,35 & 53,85 & $149,48^{*}$ & 5,44 & 6,51 & $-16,34^{*}$ \\
\hline CCP 06 x CCP 09 & 123,97 & 38,30 & $223,71^{*}$ & 151,59 & 46,56 & $225,54 *$ & 5,93 & 6,64 & $-10,58 *$ \\
\hline CCP 06 x C1P3 & 103,93 & 50,28 & $106,72 *$ & 164,59 & 63,34 & $159,85^{*}$ & 7,89 & 6,92 & $13,93 *$ \\
\hline CCP 06 x P399E & 111,72 & 64,98 & $71,93^{*}$ & 122,92 & 78,49 & $56,61^{*}$ & 5,58 & 6,17 & $-9,53^{*}$ \\
\hline CCP 76 x CCP 1001 & 55,38 & 42,90 & 29,10 & 79,62 & 62,38 & 27,64 & 6,87 & 6,72 & 2,36 \\
\hline CCP $76 \times$ C1P3 & 23,73 & 43,83 & $-45,85$ & 41,00 & 63,43 & $-35,37$ & 7,49 & 7,64 & $-2,03$ \\
\hline CCP 76 x P399E & 32,17 & 58,53 & $-45,04$ & 39,02 & 78,58 & $-50,35^{*}$ & 6,28 & 6,89 & $-8,87^{*}$ \\
\hline CCP 09 x CCP 1001 & 89,13 & 40,51 & $120,01^{*}$ & 121,07 & 55,09 & $119,76^{*}$ & 6,76 & 6,84 & $-1,21$ \\
\hline $\mathrm{CCP} 09 \times \mathrm{C} 1 \mathrm{P} 3$ & 53,45 & 41,44 & 28,98 & 81,59 & 56,15 & 45,31 & 7,87 & 7,77 & 1,28 \\
\hline CCP 09 x P399E & 100,69 & 56,14 & $79,35^{*}$ & 136,78 & 71,29 & $91,85^{*}$ & 7,05 & 7,02 & 0,36 \\
\hline CCP 1001 x CCP 06 & 171,67 & 49,35 & $247,86^{*}$ & 203,96 & 62,29 & $227,45^{*}$ & 6,16 & 5,99 & 2,74 \\
\hline CCP 1001 x CCP 76 & 60,57 & 42,90 & 41,18 & 87,54 & 62,38 & 40,33 & 7,11 & 6,72 & $5,85^{*}$ \\
\hline CCP 1001 x CCP 09 & 113,43 & 40,51 & $180,00^{*}$ & 135,82 & 55,09 & $146,53^{*}$ & 6,34 & 6,84 & $-7,32^{*}$ \\
\hline CCP 1001 x C1P3 & 60,00 & 52,49 & 14,30 & 77,25 & 71,87 & 7,48 & 7,07 & 7,13 & $-0,88$ \\
\hline CCP 1001 x P399E & 101,09 & 67,20 & $50,44^{*}$ & 129,16 & 87,02 & 48,43 & 6,32 & 6,38 & $-0,89$ \\
\hline CCP 76 x CCP 06 & 102,00 & 40,68 & $150,72 *$ & 131,33 & 53,85 & $143,87^{*}$ & 6,62 & 6,51 & 1,69 \\
\hline CCP 09 x CCP 06 & 161,31 & 38,30 & $321,22 *$ & 209,01 & 46,56 & $348,87^{*}$ & 6,40 & 6,64 & $-3,58 *$ \\
\hline CCP 09 x CCP 76 & 27,67 & 31,85 & $-13,12$ & 43,00 & 46,66 & $-7,83$ & 6,99 & 7,36 & $-4,98^{*}$ \\
\hline \multicolumn{10}{|l|}{ Pais } \\
\hline PCP 06 & 47,13 & - & - & 53,76 & - & - & 5,79 & - & - \\
\hline PCP 76 & 34,23 & - & - & 53,94 & - & - & 7,23 & - & - \\
\hline PCP 09 & 29,46 & - & - & 39,37 & - & - & 7,49 & - & - \\
\hline PCP 1001 & 51,57 & - & - & 70,81 & - & - & 6,20 & - & - \\
\hline PC1P3 & 53,42 & - & - & 72,93 & - & - & 8,06 & - & - \\
\hline PP399E & 82,83 & - & - & 103,22 & - & - & 6,55 & - & - \\
\hline Heterose média (\%) & - & - & $98,01 *$ & - & - & $96,97 *$ & - & - & $-2,11$ \\
\hline
\end{tabular}

* Significativo a $5 \%$ pelo teste $t$. 
Os híbridos anão $\mathrm{x}$ anão que mais se destacaram foram CCP 06 x C1P3, CCP 09 x P399E e CCP 09 x CCP 06, sendo os mais promissores para o programa de melhoramento populacional e clonal do cajueiro, pois apresentaram as maiores produtividades associadas a desempenhos desejáveis para os outros caracteres. Por outro lado, os piores foram CCP 76 x C1P3, CCP 76 x P399E e CCP 09 x CCP 76.

Com esses resultados, infere-se que a heterose ou vigor híbrido por meio de hibridações influencia os caracteres de altura das plantas, número e produtividade de castanhas do cajueiro, possibilitando a obtenção de ganhos genéticos significativos no processo seletivo. Essa prática viabiliza a obtenção de clones comerciais com características desejáveis, pela exploração imediata dos efeitos heteróticos em programas de seleção clonal, bem como a formação de populações-base para o programa de melhoramento populacional do cajueiro.

\section{CONCLUSÕES}

a) Há presença de efeito heterótico em cruzamentos de cajueiro anão precoce para os caracteres altura da planta, diâmetro da copa, número de castanhas por planta e produtividade.

b) É possível obter populações e indivíduos com características desejáveis pela exploração do vigor híbrido por meio de hibridações controladas entre genótipos de cajueiro anão precoce.

c) Os híbridos CCP 06 x C1P3, CCP09 x P399E e CCP09 x CCP06 são os mais promissores para a seleção clonal e formação de populações-base no programa de melhoramento do cajueiro.

\section{REFERÊNCIAS BIBLIOGRÁFICAS}

ALLARD, R. W. Princípios do melhoramento genético das plantas. 2. ed. São Paulo: Edgar Blucher, 1971. $381 \mathrm{p}$.
BREWBAKER, J. L. Genética na agricultura. São Paulo: Polígono, 1969. 217 p.

BARROS, L. M.; PAIVA, J. R.; CRISÓSTOMO, J. R.; CAVALCANTI, J. J. V. Hibridação em caju. In: BORÉM, A. (Ed.). Hibridação artificial de plantas. Viçosa: UFV, 1999. cap. 9, p. 191-220.

CAVALCANTI, J. J. V.; PINTO, C. A. B. P.; CRISÓSTOMO, J. R.; FERREIRA, D. F. Análise dialélica para avaliação de híbridos interpopulacionais de cajueiro. Pesquisa Agropecuária Brasileira, Brasília, v. 35, n. 8, p. $1567-1575,2000$.

DAMODARAN, V. K. Hybrid vigour in cashew (Anacardium occidentale L.). Agricultural Research Journal of Kerala, Kerala, v. 13, n. 2, p. 195-196, 1975.

FEHR, W. R. Principles of cultivar development. New York: Macmillan, 1987. p. 115-119.

HALLAUER, A. R.; MIRANDA FILHO, J. B. Quantitative genetics in maize breeding. Ames: lowa State University, 1981. p. 337-373.

MANOJ, P. S.; GEORGE, T. E. Heterosis in cashew (Anacardium occidentale L.). Cashew, Kerala, v. 7, n. 3, p. 7-9, 1993.

PATERNIANI, E. Estudos recentes sobre heterose. São Paulo: Fundação Cargill, 1974. 36 p. (Fundação Cargill, Boletim 01).

STEEL, R G. D.; TORRIE, J. H. Principles and procedures of statistics. 2. ed. New York: McGraw-Hill, 1980. 633 p.

STRICKBERGER, M. W. Genetics. 3. ed. New York: Macmillan, 1976. 